\title{
The Development of Ethnographic Drama to Support Healthcare Professionals
}

\author{
Lisen Dellenborg and Margret Lepp
}

\begin{abstract}
Авstract: This article describes the development of ethnographic drama in an action research project involving healthcare professionals in a Swedish medical ward. Ethnographic drama is the result of collaboration between anthropology and drama. As a method, it is suited to illuminating, addressing and studying professional relationships and organisational cultures. It can help healthcare professionals cope with inter-professional conflicts, which have been shown to have serious implications for individual well-being, organisational culture, quality of care and patient safety. Ethnographic drama emerges out of participants' own experiences and offers them a chance to learn about the unspoken and embodied aspects of their working situation. In the project, ethnographic drama gave participants insight into the impact that structures might have on their actions in everyday encounters on the ward.
\end{abstract}

KeYwords: action research, collaboration, conflicts, ethnographic drama, hospital ethnography, inter-professional relations, professional development

\section{The Problem: Inter-Professional Conflict Influencing Quality of Care}

Healthcare professionals are involved in conflicts and ethical dilemmas that call for their judgement in their everyday work. Complicating the situation, these conflicts and dilemmas are often related to hierarchies and power relations within and between professional groups. The conflicts have serious implications for individual well-being, inter-professional relations, organisational culture, quality of care and patient safety (Kim et al. 2016). In the ward under study, we could clearly see that conflicts due to organisational culture had a negative influence on individual well-being and quality of care:

The care environment suppressed multi-professionalism ... by creating demarcated routines rather than holistic care. ... In particular, the RNs [the nurses] reacted to the restriction of choice with feelings of guilt and inadequacy. They felt trapped in an ambivalent state between a desire for status achieved through biomedical knowledge, technical skill and adherence to routines, and their professional per- ception of good care, which included marginalised nursing perspectives. ... In the example of the terminally ill patient who died during the morning routines, the nurses tried to squeeze in care of the dying patient with all of the other routines and the medical rounds. ... They struggled with their conscience, knowing that the inevitable event of death seldom gives way to the routines. ... Because of the stress and importance attached to routines, two RNs prioritised morning routines over palliative care. (Wolf et al. 2012: 7-8)

A problem in the healthcare literature is that the subject of power that permeates both care environments and inter-professional relations in various ways has not been sufficiently addressed (Kim et al. 2016). Furthermore, research on healthcare conflicts generally lacks theoretical grounding and a conceptual framework (Paradis and Whitehead 2015). Consequently, these conflicts need to be studied and addressed by further research on how to support healthcare professionals in their work, the aim being to improve inter-professional relations, cooperation, and quality of care, and to contribute to theory-building. 
This article provides an example of how drama and ethnography can be combined into ethnographic drama and introduced into healthcare settings for research on how to support healthcare professionals in their everyday work. Kirsten Hastrup (2017: 316) suggests that collaboration between anthropology and other disciplines 'may potentially affect and expand the anthropological field, and hence anthropological knowledge'. We show in this article how the collaboration between anthropology and drama may expand knowledge-making within anthropology as well as within drama. Furthermore, in using James McCalman and David Potter's (2015: 216) metaphor of cultivation for organisational transformation, ethnographic drama may present anthropologists with the possibility of observing events in which seeds are sown that may eventually sprout change. However, for them to flourish in the future they will need 'everyday reframing' (see Alvesson and Sveningsson 2008), and they will not reach their full potential if the care context remains the same (Wolf et al. 2012).

\section{The Approaches: Hospital Ethnography and Drama}

\section{Hospital Ethnography}

Increasingly since the fifties and the development of Max Gluckman's Manchester school, research interest within anthropology has widened from mostly being concerned with people living in rural, typically non-European settings, to people living in an urban, Western settings (Messerschmidt 1981; Skott 2013). Importantly, there is now critical awareness within anthropology of the biases that have shaped the discipline and led to studies of 'others' as 'cultural' beings, and to its overlooking of its own 'cultural foundations and cultural dimensions at home' (Zaman 2008: 143). Anthropological field sites now include global phenomena such as media consumption (Gemzöe 2004), indigenous people's political identity-building on the Internet (Landzelius 2006), refugee camps (Gren 2009), theme parks (Appelgren 2007) and various contemporary Western and non-Western organisational settings (Garsten and Nyqvist 2013) such as hospitals and hospital wards (Zaman 2008; Wolf et al. 2012).

Hospital ethnography has grown out of a concern to understand the ways that wider social and cultural processes in a certain society are played out in its hospital settings (Long, et al. 2008; Rapport 2009; Rice 2003; Street and Coleman 2012; Van der Geest and
Finkler 2004). It is thus a research area that describes and analyses hospitals as culturally constructed domains that need to be understood in their wider social, cultural, historical and political contexts.

Ethnography is defined in diverse ways and used in other disciplines than anthropology. For instance, it is used in education (Hammersley 2017) and nursing (Roper and Shapira 2000). Common to the various definitions is the objective of understanding the phenomenon studied from the local point of view in its wider sociocultural context using participant observation as the main method and fieldwork as the main strategy. This implies deep involvement in people's daily life over a period of time (Borneman and Hammoudi 2009; Dellenborg 2013; Nässén 2013). Ethnography is thus particularly apt for the study of people's everyday lives, that is, the study of human interactions and experiences (Turner and Bruner 1986).

\section{Drama}

Drama as pedagogy can stimulate life-long learning skills that enhance the personal development and professional attitudes of students and healthcare professionals (Arveklev et al. 2015). Both drama and ethnography concern lived experience and take the participants' own views as their starting point. Furthermore, drama can be understood as the pedagogy of experience, and can thus be related to experiential learning (Morrison et al. 2013). David A. Kolb (1984: 38) describes experiential learning as 'a process whereby knowledge is created through the transformation of experience'. Central to learning through drama is reflective thinking; in drama, learning is not only the experience itself, but the reflection related to that experience (Bagshaw et al. 2007). Importantly, emotions and cognition are understood as equally important for this reflection. Drama and its content and process can thus be described as follows:

The content of Drama is human relationships, interactions containing both conflict and power. Drama operates through invoking both cognitive understanding and emotional empathy, where participants imitate and refract life through improvised, fictional contexts and situations, integrating thoughts, actions and feelings. (Burton et al. 2015: 3)

The effectiveness of drama for professional development is documented. For example, forum theatre was shown to be a useful learning medium with regard to promoting teamwork and collaboration in the radiological intervention field (Lundén et al. 2017). In addition, drama has been used in nursing education 
to prepare students in both the first and second cycle for their future nursing roles (Arveklev 2017).

\section{Forum-Play}

The term forum-play, which we used in the project, is inspired by Augusto Boal's (1992) concept of forum theatre. Forum theatre was developed explicitly as a medium for social change. It is a pedagogical form of applied theatre in which the audience members, who are referred to as the 'spect-actors' because they are both actors and spectators, are asked to enter the performance and explore alternative interactions by taking over the roles of the actors. These interactions may lead to a more positive outcome than the one presented in the original scenario (Boal 1992). In the forum-play, situations are drawn from the participants' own stories, views, and real lives. The situations are improvised and illustrated to discuss conflicts or ethical dilemmas. The forum-play utilises an open-ended dramatised story to invite participants' reactions so that they can help the participants change the process of a conflict, or explore and possibly reduce the level of a conflict through various alternative actions (Burton et. al. 2015).

\section{Ethnography and Drama}

There are many variations of the combination of ethnography and drama. Common to the various forms is the objective of using ethnographic knowledge for a contextualised understanding of the scenarios. The various combinations often sound the same, which might be confusing. For instance, the anthropologist Victor Turner together with Edith Turner developed performance ethnography as a medium for learning. They conducted drama workshops with students, in which they dramatised life-cycle rituals in order to teach ethnography and develop an inner understanding of the people for whom these rituals are meaningful (Turner and Turner 1982). In particular, Victor Turner (1986) explored the relationship between theatre, everyday life, and embodied knowledge. Everyday life, according to Turner (1982), is a form of theatre, not in a metaphorical sense but as a series of performances of which the body has knowledge. He emphasised that learning from everyday life therefore demands bodily engagement and action: 'One learns through performing, then performs the understanding so gained' (1982: 94).

Norman K. Denzin (2003: 14) has profoundly developed performance ethnography together with critical pedagogy as political tools to 'give a voice to the subaltern [and] move people to action' - the main goal being the use of ethnography for social change, justice and democracy. Many social scientists and performance artists have since then been influenced by both Turner and Denzin (see, e.g., Harrop and Njaradi 2013). Tara Goldstein (2010), for example, developed performance ethnography as a pedagogical means to experiment with various stereotypical understandings in order to counteract racism and homophobia among high school students. The strength of her variation, called performed ethnography, lies in ethnographic research and active participation (Goldstein 2008); the students' active participation in the performance and the following discussion provoked critical analysis among the students and created the possibility for them to change their attitudes and behaviours.

Other variations of combining drama and ethnography have had the aim of counteracting social injustice and the stigmatisation of people suffering from various forms of illness are called ethnodrama (Mienczakowski 2001) and ethnotheatre (Saldaña 2008). These approaches have been used as innovative ways of reporting and sharing research results. An important difference from the above-mentioned variations is that the people concerned, for instance healthcare professionals, are spectators only and not participants in the play (Mienczakowski 2001; Saldaña 2008). Other forms of ethnotheatre (e.g. Belliveau and White 2010) are more purely pedagogical, aiming at finding new ways for students to learn. In carrying out this action research project, we were, as mentioned above, inspired by Augusto Boal, as well as by Turner (1982) and Denzin (2003).

\section{Anthropology and Social Change}

As a discipline, anthropology with its premise of relativism has generally had a problematic relationship with the issue of anthropologists becoming engaged in social change. The pertinent questions here have to do with in whose interest social change is supposed to be and from what position we are to "identify what is good and what is bad and to allocate reward and punishment" (D'Andrade 1995: 399; see also Strathern 1987). The difficulty of reconciling informants' cultural understandings of certain practices - such as headhunting and female genital cutting - with Western understandings of those practices (Rosaldo 2000; Dellenborg 2004) has led many to criticise anthropologists for their cultural relativism (Edgerton 1992; Shestack 2000). Cultural relativism is 
not, however, the same as moral or ethical relativism: searching for the meanings that practitioners attach to a ritual and practice does not by definition imply acceptance or refusal to take a stance on said ritual or practice (Geertz 1984; Gordon 1991; Rosaldo 2000).

Importantly, engagement for social change should be carried out together with those whom it concerns and be based on a thorough understanding of 'how things work' (D'Andrade 1995: 408), that is, on knowledge of the local context, the diverse social actors' voices, and power positions (Dellenborg 2007; Dellenborg and Malmström 2013). However, many anthropologists are indeed engaged in the struggles for improved life conditions and social justice among the people in their field (see, e.g., Cowan et al. 2001 and Kulick and Rydström 2015; see also Denzin 2003 and Goldstein 2008 already mentioned above). Medical anthropologists have been important actors for research on finding culturally accepted ways to improve health in poorer parts of the world (Kiefer 2006). International development aid organisations have an expressed interest in anthropology, with its thorough understanding of the milieus and the contexts of the implementation projects that it may offer.

However, knowledge about the finer aspects of social life and its complexity requires time to acquire, time that development experts seldom seem to have. Attempts at synthesis have been made in the form of KAP (knowledge, attitudes, practices), RRA (rapid rural appraisal) and PRA (participatory rural appraisal). Yet these methods are problematic, as they bear 'a remote resemblance to anthropology but simplified into a kit' (de Sardan 2005: 210). A professor in anthropology with a great deal of experience in development work, Jean-Pierre Olivier de Sardan recommends that development organisations have anthropologists who are already specialists - having previously undertaken long-term studies of the region - make brief evaluations instead of letting an expert who is unfamiliar with the region use PRA. 'Anthropology', he says, 'can help action only if it maintains high standards of quality' (2005: 211). Significantly, the action research project is based on long-term ethnographic fieldwork at the ward, and the identification of problems and solutions for change to occur was developed in a collaboration between the researchers and those whom their research concerned: the healthcare professionals and their management.

\section{The Project}

\section{Description of The Forum Project}

The action research project that developed from the hospital ward management leaders' invitation to the research group to support them in improving communication in the ward was named The Forum Project. The development of ethnographic drama in this project thus started within an ongoing ethnographic research project that was a collaboration between healthcare professionals on a medical ward in a hospital in Sweden and a research group from a Swedish university. The project's intention was to create a forum for reflection and change for better communication in the ward using ethnographic fieldwork and drama in the form of a forum-play. The Forum Project comprised four action research cycles: Cycle 1 in 2008, Cycles 2 and 3 in 2011, and finally Cycle 4 in 2012. The activities of each cycle are described in Table 1.

Table 1. The Project's Four PAR Cycles

Cycle 1

- Aim: To improve communication and understanding for transcultural healthcare encounters on the ward.

- Activities: Inter-professional group discussions.

- Participants: RNs, NAs and physicians.

- Analysis: The complexity in healthcare encounters and the diversity represented by patients in terms of language spoken, cultural understandings, religious belonging, age and gender left the healthcare professionals confused as to what kind of knowledge they needed to increase their transcultural understanding and communication competence. It was clear that communication patterns were influencing patient encounters in general in a negative way. The results are described in a study by Dellenborg and colleagues (2012).

- Outcome: The researchers recommended that the ward's management arrange for regular sessions to be held between staff and researchers with the aim of improving encounters in the ward through critical self-reflection and elaborated discussions on the meaning of diversity and difference. It was decided to organise opportunities for staff to reflect on these issues in the form of drama workshops. 
Cycle 2, step 1

- Aim: To improve communication between healthcare professionals and patients and their families.

- Activities: Drama workshops - seven drama workshops of three hours each in groups of approximately 12 participants. A total of 15 forum-plays were performed.

- Participants: RNs and NAs.

- Analysis: The staff strove to 'do the right thing' according to their values and competencies, but were hindered from doing this by stress, routines, language difficulties, misunderstandings, poor communication, and hierarchies related to the different healthcare professions.

- Outcome: The ward's management and the researchers planned for professional group discussions on themes that had been produced in the forum-plays: inter-professional relations and communication; how to be flexible in relation to routines; and how to make the patient's voice heard and establish good relations with patients' families.

Cycle 2, step 2

- Aim: To improve communication and relations with patients and their families on one hand, and within the staff group on the other.

- Activities: Staff conference with inter-professional group discussions.

- Participants: RNs, NAs and physicians.

- Analysis: There was a need for more knowledge about and understanding of each other's everyday work; time for reflection within the team; suggestions for modification of routines to meet patients' needs and save healthcare professionals' time; and the creation of structures improving the medical round for staff's and patients' well-being and communication.

- Outcome: A second series of drama workshops that would include physicians was arranged.

\section{Cycle 3}

- Aim: To improve inter-professional communication, healthcare encounters and teamwork.

- Activities: Drama workshops. Five workshops of three hours each in groups of approximately 12 participants. In total, 11 forum-plays were performed.

- Participants: RNs, NAs and physicians. Physicians participated in three out of five workshops. No senior physicians participated.

- Analysis. There is a need to improve inter-professional relations and teamwork.

- Outcome: The researchers' ethnographic knowledge of the ward indicated that the professional groups easily ended up in accusations and defensiveness while discussing team-related problems in interprofessional groups. The researchers therefore recommended that the ward's management arrange for intra-professional group discussions on teamwork in a staff conference.

\section{Cycle 4}

- Aim: To reflect on the aim of the healthcare team, the professionals' view of their roles in the team, and obstacles to and possibilities for implementing these roles.

- Activities: Intra-professional group discussions at a staff conference.

- Participants: RNs, NAs and physicians (senior and junior physicians discussed in separate groups, as they had different roles in the team and their relations were marked by hierarchy).

- Analysis: The expressed aim of the team ('to give patients the best care using all professions' competencies') was difficult to fulfil due to hierarchical order in the team and organisational factors. Nurses differed from physicians in their wish to see patients as part of the team. At the time of the study, patients were generally informed about, rather than made partners in, the creation of a care plan.

- Outcome: As in every cycle, the ward's management was given a written report from which they were to continue working to improve teamwork and healthcare encounters on the ward. 
During Cycle 3, the problems that were encountered trying to get physicians to participate in the drama workshops were unfortunate for the project and the development of teamwork on the ward. The nurses' management leader prioritised the drama workshops as occasions for professional competence development for the nurses. The physicians, however, were given no time by their management to participate in the drama workshops. The reason given for this was the scarcity of physicians. The few who managed to participate had to do so parallel to their ordinary tasks. In one case, a physician was released at the last moment from their ordinary tasks after a call from the anthropologist (LD) to the physicians' management leader. We gather that the physicians' management was not negatively inclined towards the workshops, as they had made the decision to participate in the project workshops, but did not consider them important enough to prioritise them. Looking at this lack of physician participation in the drama workshops in a wider context, we note that physicians are generally known to be a professional group that is difficult to engage in organisational work (Bååthe 2016). Yet their engagement is critical, as they are in a powerful position to hinder improvements in organisational work (Bååthe and Norbäck 2013). This has been explained as partly being due to physicians' training and partly due to a traditional lack of organisational and collective aspects of the profession. Primarily, their training focuses on the development of clinical skills (Snell et al. 2011: 952). Physicians have been trained to think of change in relation to individual patients, medicine and treatment, and not in relation to the wider organisation. A fact strengthening this focus is that biomedicine is a science and that its epistemology is focused on 'the solitary body of the individual sick person', which creates difficulties when advancing the important effect of social relations on illness (Kleinman 1995: 37) and also, we add, in the clinic. Accordingly, it is rare that physicians' management supports them in their efforts to take part in work for organisational change (Bååthe 2016). In our project, this circumstance was unfortunate, as physicians' voices were not heard and the opportunity for important inter-professional dialogue was lost. We could see that the lack of physician participation in the drama workshops reflected the ethical dilemmas and communication failures in the ward as narrated and performed by the nurses in the drama workshops.

\section{Context of the Project}

The context was a medical emergency ward at a university hospital in Sweden. The hospital had a catchment area with over two hundred and fifty thousand residents. The healthcare professionals in the project worked on the medical emergency ward, which was divided into an emergency care unit for the most critically ill and an intermediate care unit for patients who were in rehabilitation or whose condition had been diagnosed as not critical. However, due to organisational changes in the clinic, old and very sick patients - even those in need of palliative care - were cared for in the ward as well.

The ward environment was high-tech, and the treatment regimen offered full supervision of the patients and preparedness for emergency intervention by the relevant personnel. At the time of this project, the ward had 36 beds. The average stay for in-patients needing care was 4.4 days. The personnel consisted of 60 Registered Nurses (RNs), 40 nursing assistants (NAs) and 43 senior and junior physicians. A senior physician is a specialist. A junior physician, called a resident, might be a medical student practising to gain their licence 18 to 21 months after qualifying as a physician, a newly certified physician or a physician in specialist training. About $25 \%$ of the RNs and $60 \%$ of the physicians were men. The overwhelming majority of the RNs and NAs were women. The healthcare professionals worked in teams consisting of two RNs and two NAs caring for ten patients together with a senior physician and a junior doctor .

\section{Methods and Methodology}

\section{Participatory Action Research}

The project was carried out as participatory action research (PAR), which meant that problems were defined and solutions sought out by collaboration between the researchers and the healthcare professionals. The aims of this research were to improve practice and study the effects of the actions taken. Action research has a long history and was first described by Kurt Lewin (1946: 202) as 'comparative research on conditions and effects of various forms of social action and research leading to social action'. PAR involves a spiral of cycles (planning - acting - observing - reflecting - replanning), with critical reflection being an important step in each cycle (Kemmis and McTaggart 2005). As the purpose of PAR is to contribute to change in a particular social 
context, the combination of drama with ethnographic methods and methodology is well suited. Our project consists of four PAR cycles.

\section{Ethnographic Fieldwork}

In parallel with the four PAR cycles, ethnographic fieldwork with participant observation was conducted on the ward by the first author, LD. The purpose of the fieldwork was to understand the healthcare environment from the perspective of the healthcare professionals - physicians, RNs, and NAs - and the patients. Participant observation was also conducted during the drama workshops by three anthropologists in the research group (LD, KN [Dr Kristina Nässén] and CS [Dr Carola Skott]), the last two also having professional experience as RNs.

The methodology of the ethnographic approach includes reflexivity, description, comparison and interpretation, an inner perspective, and a relativistic stance (Scott-Jones and Watt 2010; Skott 2013). Reflexivity implies a demand on the researchers to be aware of their own pre-understandings as well as positionality, including sex and gender identity, age, socio-economic class and ethnicity, lest the researchers risk reproducing their own understanding of the phenomenon. Awareness of positionality proved critical, as the first author needed to draw on different aspects of her identity in order to build confidence with the various healthcare professional groups in the project: the physicians, the RNs and the NAs (Dellenborg 2013).

Being the fieldworker, LD was in charge of presenting research findings, leading group activities at the healthcare staff conferences and ensuring the transparency of the research process. Important for the action research process as well as the development of ethnographic drama was that the research group (LD, ML, KN, CS) carried out all analyses collectively, which resulted in group ethnography as described by Gemzöe (2004) and documented by Skott and colleagues (2013).

\section{The Drama Workshop}

The particular form of drama workshop used in this project built on earlier research in the field of drama and conflict management (Burton et al. 2015). The drama workshop was conducted in a classroom in the hospital, which was cleared of tables, an open space that provided room for movement and performance. Each workshop lasted for three hours and was facilitated by ML (an authorised drama teacher, $\mathrm{RN}$ and researcher). Each workshop started with the participants sitting in a circle and sharing presentations and expectations; this was followed by warmup games that included participants sharing their names and life histories (in pairs) and improvising work scenes using role reversal. The warm-up games were followed by the preparations for forum-plays. In pairs, participants exchanged a story of conflict from their everyday work on the ward. In groups of three to five, the participants were then given 30-45 minutes to prepare a scenario for a forum-play. Each workshop entailed two, or at most three, forumplays. Staff members were given opportunities to intervene actively in each of the plays performed (Lepp and Dellenborg 2013).

\section{Ethical Considerations}

Permission to conduct the study was obtained from the Regional Ethical Review Board in Gothenburg, Sweden (046-08). The investigation conforms to the principles outlined in the Declaration of Helsinki developed by the World Medical Association. Concerning participant observation during the drama workshops, the participants were informed orally that participation was voluntary, that an ethnographer would be taking field notes during the workshops to be used for scientific articles and that their identities would be protected. On the ward, the staff and the patients received written and oral information about the field study on numerous occasions in an attempt to reach them all. Being aware of the ethical sensitivity that accompanies observational studies in hospital wards, at the slightest apprehension that a staff member or patient might feel uneasy about her presence LD changed for another unit in the ward. At the time of the drama workshops, the participants were familiar with LD. Although some expressed an uneasiness about drama, no one expressed any apprehension about being observed by the researcher.

\section{Findings and Reflections}

The idea of drama workshops was a result of the activities in Cycle 1. In Cycles 2, 3 and 4, the professionals were given the opportunity to reflect back and forth together with the researchers in drama workshops and professional group discussions. Through fieldwork (carried out during Cycles 2, 3 and 4) and other activities with the healthcare professionals, the researchers acquired rich ethnographic knowledge of 
the ward. This knowledge was central for the development of ethnographic drama.

\section{The Development of Ethnographic Drama}

The development of ethnographic drama is described and presented through the process of:

(1) Combining ethnography and drama;

(2) Using the forum-play as an example;

(3) Describing the healthcare professionals' interpretative process;

(4) Describing the researchers' interpretative process; and

(5) Formulating ethnographic drama.

\section{(1) Combining Ethnography and Drama}

Progressively during the last three cycles of the Forum Project, the research group discovered that the combination of drama and ethnography was particularly creative way to produce new knowledge about the healthcare context and to support healthcare professionals in improving their communication with patients and each other. Carrying out participant observation at the drama workshops gave researchers the opportunity to share and listen to the participants' own narratives concerning what was important for them in their everyday work.

Problematic and conflicted situations in encounters between healthcare professionals and patients and their families were significant, which was expected from the inter-professional group discussions held in Cycle 1. However, as many as half of the forum-plays concerned communication failures and conflicts between professionals and also conflicts related to routines. In fact, conflicting professional relations were put forward by participants as a major hindrance in their everyday work. This circumstance drew the researchers' attention to the need of working on inter-professional relations.

Common themes in the forum-plays on conflicting inter-professional relations were mutual expectations that were not fulfilled or not expressed within the team, conflicts that were not communicated, discussed or even acknowledged by counterparts. Although there were examples of failed co-operation in relations between all professional groups, the RNs and NAs specifically raised experiences of failed communication and co-operation with physicians. The RNs voiced the dilemma of having little authority in relation to physicians and yet much responsibility in relation to the patients and their families; in various ways, they expressed feeling pinioned by physicians.
These forum-plays also illustrated challenging situations related to routines. These situations did not instantaneously point to failing professional communication. Yet, in the process of staff reflection it became clear that communication had failed within and between teams on the ward. These forum-plays made the participants reflect on how failed communication between professionals may harm patients and on how they may actually exert power over patients when sticking unreflectively to routines. The interactions and discussions generally went from accusing counterparts to searching for alternative actions and, at best, to reflecting on the problems and coming to an understanding of the complexity of the situations and achieving insight into their own roles in the conflicts.

This is where a forum-play generally ends when led by drama teachers alone. The co-operation with anthropologists and the combination with ethnography gave the researchers an opportunity to understand the forum-plays in the wider context of the hospital environment. This, in turn, gave the researchers the means to support the management and staff better in improving communication and co-operation on the ward. We shall now describe how the combination of ethnography and the forumplay was developed into ethnographic drama. We shall also describe the particular kind of knowledge gained from this combination.

\section{(2) Using the Forum-Play as an Example}

In order to describe the development of and the knowledge gained from ethnographic drama, we shall use one forum-play as an example. The forumplay concerned an elderly, severely ill patient and his visiting elderly wife. The ethical dilemma was that a young nurse, Karin, found herself prohibited by Eva, a nursing colleague, from doing what she thought would be best for the patient and his wife:

A registered nurse, Karin, 25 years old, comes into a single patient room where the severely ill patient Kurt is lying in his bed. Kurt is 87 years old and in a palliative phase and very anxious. His wife Ada, 87 years old, is sad and asks Karin if someone can stay with them in the room for a while to calm Kurt. The registered nurse goes to ask her colleague, Eva, 45 years old, who has worked on the ward for a long time, for advice. The answer she gets is that there is no nurse who can sit with them and that 'we don't pursue that form of care here'. (Workshop 1, forumplay no. 2, Cycle 2)

As stated above, in the forum-play the audience members intervene in the play with suggestions of 
alternative ways to manage the situation so as to find constructive solutions together. The play was run again and now, as the floor was opened for the audience members to intervene, several voices in the audience protested loudly when Karin was hindered by Eva from solving the situation by searching for a nurse to support the elderly couple with some company: 'We can't leave the patient, can we?' 'We should call for support from another nurse to come and stay with the couple!'

A nurse in the audience went on scene and took the role of Karin. She tried to change the scenario by calling Eva back into the patient room, and she tried to convince her to let a nurse stay with the couple. Eva still did not agree and instead proposed morphine for the patient. Her proposal induced much tension in the group. 'Why would you give the patient morphine?' someone in the audience asked Eva in an indignant tone, supported by others' humming. The person who played Eva answered that she intended to reduce the patient's anxiety. The audience was not relieved by this answer and heavily criticised her suggestion to give morphine as an alternative. They suggested that Eva might have responded differently had Karin not been a newly registered and newly employed young nurse. The participants reasoned that it was difficult to make way for new thinking on the ward. The drama leader asked Karin what she felt about being new on the ward. Karin, in character, pondered on the difficulty of acting without the support of experienced colleagues, which in this case was deciding to find a nurse to support the couple.

The play continued, and Karin now tried to act on her own and so to speak go behind the back of her colleague. She asked the staff in the other part of the ward for help, and thus managed to solve the situation. Eva, in character, stood silently and did not react negatively to Karin's action. A voice in the audience remarked with approval: 'The most experienced person does not always know best!' This remark was followed by relieved laughter in the audience. The drama leader then asked the 'actors' how they had felt taking on the different roles. The one who had played Ada said cautiously that she had just wanted help for her husband and herself. The one who had played Kurt said: 'I got more worried and uneasy ... [as the nurses disputed with each other]'. The participants were all concerned about this situation and upset by the narrative. Collectively, they wondered how a colleague would even consider leaving two elderly persons in need alone in the room. However, in the round of reflections one of the participants thoughtfully observed: 'We are very medically oriented on the ward'. In the silence that followed, the others slowly nodded their heads in agreement.

\section{(3) Describing the Healthcare Professionals' Interpretative Process}

At first glance, the professionals interpreted the problem as being about the status of the two RNs and who had the right to decide what form of care the patient should get. The audience then reflected on various aspects of power relations that coincided in the play: the length of time that these nurses had worked on the ward and the age difference between them. In the initial narrative, the younger nurse did not dare to contradict the older nurse, who was forthright about her view of how things were done on the ward: 'We don't pursue that form of care here', meaning that the ward did not undertake palliative care. She thereby claimed the privilege of interpretation. With her body language, Karin, the younger nurse, dramatised the hesitation that she felt in this situation, being hindered from doing what she thought was best for the patient and the couple; she was silent, as though frozen by the shock of her colleague's words. She did not go into the patient's room to deliver this answer.

The audience later confirmed that it is difficult to introduce new ideas on the ward. They reflected on the power relations between healthcare professionals and patients and their families, and that the latter are dependent on the professionals. Together, the audience and the nurse acting as Karin suggested a practical solution: to ask staff in other parts of the ward for help. Karin, in character, tried this and came back with an extra nurse, who was able to keep the elderly couple company for a while. They were content with having found an alternative way to handle an ethically difficult situation, a way that seems to have suited everyone. However, as the discussion continued they detected that the forum-play, rather than being just about the status of two nurses, actually concerned the wider issue of biomedicine contra care-giving on the ward. They considered the 'narrow medical thinking' on the ward and the strong medical orientation of their practice. They were discontent with the fact that medicine had priority over care-giving. Upon reflection, they saw that the forum-play illustrated this precedence as being at the expense of a holistic understanding of the patient as a person with more than just medical needs.

\section{(4) Describing the Researchers' Interpretative} Process

Interpreting the forum-play in relation to the knowledge gained from fieldwork on the ward, the re- 
searchers were able to see that the play about Karin and Eva and the couple was characteristic for that particular healthcare environment and did not just illustrate a single exceptional event. The participants' process of reflection resulted in an understanding of Eva's actions, an important insight that was not spoken aloud and did not imply acceptance, but one that helped them to make sense of her behaviour, as illustrated by the comment: 'We are very medically oriented at the ward'. Throughout the main part of the play, Eva was criticised heavily for acting strangely. However, towards the end of the play the care-givers gradually shifted their focus from Eva as an odd individual 'wrong-doer' towards self-critical reflection concerning the strong medical orientation on the ward. The use and form of the forum-play became a catalyst for issues that needed to be raised but that would normally be avoided, such as the risk of routines taking precedence over patients' needs. In the process, existing hierarchies in the ward were made visible. The participants gained insight into the impact that structures might have on their own actions in everyday encounters, actions counteracting patients' as well as professionals' well-being on the ward.

Participant observation on the ward confirms this picture; there was a strong focus on biomedical knowledge and routines as described in the lengthy block quotation from Wolf and colleagues presented at the beginning of this article. Significantly, these perspectives took precedence in multi-professional dialogue and left little room for other perspectives, such as care-giving perspectives and the patient's perspective (Wolf et al. 2012). Since the geriatric ward in the hospital had been closed, most of the emergency ward's patients were (and still are to this day) old and very ill, and some indeed palliative. However, neither the care, the number of care-givers nor the physical milieu were in any way organised so as to enable care-givers to support patients in need of palliative care.

Understood in this context, Eva's statement that palliative care was not pursued on the ward and her suggestion to give morphine rather than to support the couple with her presence do not appear that odd. The character Karin's experience of not being able to act according to her values about good care was an experience described by many RNs in informal conversations, interviews and forum-plays. The fieldworking anthropologist heard many stories about restricted choice due to structures in the ward and challenges that the RNs met in the contest between medicine and care, routines and the patient's best interests. These situations often led to moral stress (Wolf et al. 2012). There were also stories of individual care-givers striving to find ethical solutions, as Karin finally did in the forum-play. In so doing, they had to challenge the care environment and organisational prioritisations (Dellenborg 2013).

Significant for this play was that it was not until the nurses had become engaged on various levels, most importantly on an emotional level, and had made this narrative into an embodied experience that they were able to recognise the impact of structures on their actions and not simply blame the individual nurse Eva. In this healthcare environment, there was a strong tendency to blame individual care-givers rather than to see how organisational and structural factors result in conflict on the ward, such as the prioritisation of biomedical knowledge and the organisation of routines and working schedules (Dellenborg 2013; Wolf et al. 2012). The predominant goal of the Forum Project was precisely to support management and the healthcare professionals in their understanding of the lack of communication and the relational conflicts in this wider sociocultural context.

\section{(5) Formulating Ethnographic Drama}

The researchers found that the forum-play combined with ethnography gave them unexpected possibilities to learn about the unspoken and embodied aspects of life on the ward, the aspects that are difficult to put into words and those that are taken for granted (Bourdieu 1977). The use of the forum-play makes it clear that the drama leader's, the ethnographers' and the participants' pre-understandings were challenged and transformed. Through bodily acting in the forum-play, the participants co-created a common narrative 'as if' the situation were real and happening again - and at the same time different from the original event because all participants contributed with their experiences and interpretations. The forum-play provides a unique opportunity to turn personal experiences into cultural narratives. The interveners improvised according to their experiences of the ward and together created a situation that they could all recognise as 'their ward'. In the project, the ethnographic knowledge produced was broadened by every forum-play. The drama leader and the anthropologists thus became increasingly skilful in contextualising the participants' narratives and thereby in supporting them to learn to see their own actions as producing and reproducing the sociocultural structures on the ward. This insight enabled them to act differently and thereby, taking small steps, actually to contribute to change. 
Turner (1982: 94) underscored that 'there must be a dialectic between performing and learning. One learns through performing, then performs the understanding so gained'. This quotation explains how forum-play and drama are effective in the learning of alternative ways of acting. Through their engagement in the play, the participants were touched and moved, and thus gained a unique opportunity for learning. In Goldstein's study (2008), the participants' active participation in the performance and the following discussion triggered their critical analysis, which potentially led to change. In ethnographic drama, as constructed by our research group, it is essential that the participants involved are those who enact the play, but it is also important that the narratives enacted represent the participants' own experiences. By acting out their narratives, the difficulties, problems, communication failures and dilemmas experienced by the healthcare professionals in their daily work thus became concretised. Through ethnographic drama research and supervision, a process emerged that enabled the participants to gain new understanding. They learnt how to communicate and act in better ways, so that usually conflicted situations could be transformed into decent healthcare encounters with patients and their families on one hand and professionals on the other.

\section{Conclusion}

Ethnography and drama combined in the form of a forum-play is what we call ethnographic drama. Ethnographic drama turned out to be well suited to illuminating, addressing and studying relations in healthcare within and between professional groups and also between professionals and patients and their families. The method is particularly appropriate for research on and the support of healthcare professionals in their everyday work, in which conflicts turned out to be significant for inter-professional relations and for the care that was being given. Forumplay as one of the method's two cornerstones is thus particularly apt for helping healthcare professionals improve inter-professional relations, co-operation and quality of care. The method contributes knowledge about the specific context and the participants' perspectives when acting as patients, relatives and healthcare professionals. Distinctive for this version of ethnographic drama is that it is based on the participants' own experiences and narratives, and not on the ethnographers' interpretations of the same, as is otherwise typical.
In this way, drama is enriched by the ethnographic practices of fieldwork and participant observation and the possibility to interpret the drama in a wider context. Likewise, ethnography is enriched by drama and forum-play as the participants enact dilemmas 'as if' they were happening again. Combining drama and ethnography into ethnographic drama thus creates opportunities for learning in both research and healthcare practice.

\section{Acknowledgements}

We wish to thank the hospital and the ward management leaders and the healthcare professionals on the emergency ward for the opportunity to work together in this action research project. We also wish to thank The Swedish Institute for Health Sciences [Vårdalinstitutet] at Lund University, the University of Gothenburg, and the Institute for Health and Care Sciences, University of Gothenburg, which, at the time of this project, collaboratively granted the first author a position as a research assistant. This made the long-term ethnographic fieldwork on the ward possible. Warm thanks are owed to our research team colleagues, Dr Carola Skott and Dr Kristina Nässén.

Lisen Dellenborg holds a doctorate in social anthropology and is employed as a university lecturer and researcher at the Institute of Health and Care Sciences at the Sahlgrenska Academy, University of Gothenburg, Sweden. She has extensive experience with ethnographic research, having worked in Senegal on female genital cutting and in Sweden where she is currently engaged in hospital ethnography. Her areas of expertise are hospital ethnography; interprofessional communication and relations within the Swedish healthcare system; female gential cutting; gender; sexuality; ethnicity and religion.

E-mail: lisen.dellenborg@gu.se

MARgRet LePP is a registered nurse (RN), a doctor of philosophy and a professor at the Institute of Health and Care Sciences at the Sahlgrenska Academy, University of Gothenburg, Sweden, with a focus on caring pedagogy. She is also an adjunct professor at Griffith University, South East Queensland, Australia. Her areas of research include students' and healthcare professionals' learning; educational drama; internationalisation and conflict management.

E-mail: margret.lepp@gu.se 


\section{References}

Abu-Lughod, L. (1991), 'Writing Against Culture', in R. G. Fox (ed.), Recapturing Anthropology - Working in the Present (Santa Fe, NM: School of American Research Press).

Alvesson, M. and S. Sveningsson (2008), Organizational Culture: Cultural Change Work in Progress (London: Routledge).

Appelgren, S. (2007), 'Huis Ten Bosch: Mimesis and simulation in a Japanese Dutch Town' (PhD diss., University of Gothenburg, Sweden).

Arveklev, S. H. (2017), 'Drama and Learning in Nursing Education: A Study in First and Second Cycle' (PhD Diss., University of Gothenburg, Sweden).

Arveklev, S. H., H. Wigert, L. Berg, B. Burton and M. Lepp (2015), 'The Use and Application of Drama in Nursing Education - An Integrative Review of the Literature', Nurse Education Today 35, no. 7: 12-17.

Bååthe, F. (2016), 'Physicians' Engagement: Qualitative Studies Exploring Physicians' Experiences of Engaging in Improving Clinical Services and Processes' (PhD Diss., University of Gothenburg, Sweden).

Bååthe, F. and L. E. Norbäck (2013), 'Engaging Physicians in Organisational Improvement Work', Journal of Health Organisation and Management 27, no. 4: 479-497.

Bagshaw, D., B. Burton, M. Friberg, A. Grünbaum, M. Lepp, J. O'Toole and J. Pillai (2007), Bridging the Fields of Drama and Conflict Management in DRACON International, Empowering Students to Handle Conflicts through School-Based Programmes (Studia Psychologica et Paedagogica, Series Altera CLXX) (Malmö: Malmö University Electronic Publishing). http:// dspace.mah.se/bitstream/2043/5975/1/drac06nov.pdf.

Belliveau, G. and V. White (2010), 'Performer and Audience Responses to Ethnotheatre: Exploring Conflict and Social Justice' Arts Praxis 2. https:// steinhardt.nyu.edu/music/research/artspraxis/2.

Boal, A. (1992), Games for Actors and Non-Actors (London: Routledge).

Borneman, J. and A. Hammoudi (eds.) (2009), Being There: The Fieldwork Encounter and the Making of Truth (Berkeley: University of California Press).

Bourdieu, P. (1977), Outline of a Theory of Practice (Cambridge: Cambridge University Press).

Burton, B., M. Lepp, M. Morrison and J. O'Toole (2015), Acting to Manage Conflict and Bullying: Effective Evidence-Based Strategies (London: Springer).

Cowan, J. K., M. B. Dembour and R. A. Wilson (eds.) (2001), Culture and Rights: Anthropological Perspectives (Cambridge: Cambridge University Press).
D'Andrade, R. (1995), 'Moral Models in Anthropology', Current Anthropology 36, no. 3: 399-408.

Dellenborg, L. (2004), 'A Reflection on the Cultural Meanings of Female Circumcision: Experiences from Fieldwork in Casamance, Southern Senegal', in S. Arnfred (ed.), Rethinking Sexualities in Africa (Uppsala, Sweden: The Nordic Africa Institute), 79-96.

Dellenborg, L. (2007), 'The Multiple Meanings of Female Initiation: "Circumcision" among Jola Women in Lower Casamance, Senegal (PhD Diss., University of Gothenburg, Sweden).

Dellenborg, L. (2013), ‘Fältarbetets betydelse och villkor' [Fieldwork: Meaning and Circumstances], in C. Skott, L. Dellenborg, M. Lepp and K. Nässén (eds.), Människan i vården: Etnografi, vård och drama [The Person in Healthcare: Ethnography, Care and Drama] (Stockholm: Carlssons).

Dellenborg, L., C. Skott and E. Jakobsson (2012), 'Transcultural Encounters in a Medical Ward in Sweden: Experiences of Health Care Practitioners', Journal of Transcultural Nursing 23, no. 4: 342-350.

Dellenborg, L. and M. Malmström (2013). 'Att äga sin förändring: Kvinnlig omskärelse/könsstympning och mänskliga rättigheter' [To Own the Processes of Change: Female Circumcision / Female Genital Mutilation and Human Rights] in P. de los Reyes, M. Eduards and F. Sundevall (eds.), Internationella relationer: könskritiska perspektiv [International Relations: Gender-Critical Perspectives] (Stockholm: Liber), 218-234.

Denzin, N. K. (2003), Performance Ethnography: Critical Pedagogy and the Politics of Culture (Thousand Oaks, CA: SAGE).

de Sardan, J.-P. O. (2005), Anthropology and Development, (trans.) A. Tidjani Alou (London: Zed Books).

de Wit F. R., C. Lindred, L. Greer and K. A. Jehn. (2012), 'The Paradox of Intragroup Conflict: A MetaAnalysis', Journal of Applied Psychology 97, no. 2: 360-390.

Edgerton, R. B. (1992), Sick Societies: Challenging the Myth of Primitive Harmony (New York: The Free Press).

Garsten, C. and A. Nyqvist (eds.) (2013), Organisational Anthropology: Doing Ethnography in and among Complex Organisations (London: Pluto Press).

Geertz, C. (1973), The Interpretation of Culture (New York: Basic Books).

Geertz, C. (1984), 'Anti Anti-Relativism', American Anthropologist 86, no. 2: 263-278.

Gemzöe, L. (2004), Nutida etnografi: reflektioner från mediekonsumtionens fält [Contemporary Ethnography: Reflections from the Field of Media Consumption] (Nora, Sweden: Nya Doxa). 
Goldstein, T. (2008), 'Performed Ethnography: Possibilities, Multiple Commitments and the Pursuit of Rigor', in K. Gallagher (ed.), The Methodological Dilemma: Creative, Critical and Collaborative Approaches to Qualitative Research (New York: Routledge), $85-120$.

Goldstein, T. (2010), 'Snakes and Ladders: A Performed Ethnography', International Journal of Critical Pedagogy 3, no. 1: 68-113.

Gordon, D. (1991), 'Female Circumcision and Genital Operations in Egypt and the Sudan: A Dilemma for Medical Anthropology', Medical Anthropological Quarterly 5, no. 1: 3-14.

Gren, N. (2009), ‘Each Day Another Disaster: Politics and Everyday Life in a Palestinian Refugee Camp in the West Bank' (PhD diss., University of Gothenburg, Sweden).

Hammersley, M. (2017), 'What Is Ethnography? Can It Survive? Should It?' Ethnography and Education 13, no. 1: 1-17.

Harrop, P. and D. Njaradi (eds.) (2013), Performance and Ethnography: Dance, Drama, Music (Newcastle upon Tyne, UK: Cambridge Scholars Publishing).

Hastrup, K. (2017), 'Collaborative Moments: Expanding the Anthropological Field through Cross-Disciplinary Practice', Ethnos 83, no. 2: 316-334.

Kemmis, S. and R. McTaggart (2005), 'Participatory Action Research', in N. K. Denzin and Y. S. Lincoln (eds.), The SAGE Handbook of Qualitative Research (Thousand Oaks, CA: SAGE), 559-604.

Kiefer, C. W. (2006). Doing Health Anthropology: Research Methods for Health Scientists. (New York: Springer).

Kim, S., E. Buttrick, I. Bohannon, R. Fehr, E. Frans and S. Shannon. (2016), 'Conflict Narratives from the Health Care Frontline: A Conceptual Model', Conflict Resolution Quarterly 33, no. 3: 255-277.

Kleinman, A. (1995), Writing at the Margin: Discourse between Anthropology and Medicine (Berkeley: University of California Press).

Kolb, D. A. (1984), Experiential Learning: Experience as the Source of Learning and Development (Englewood Cliff s, NJ: Prentice-Hall).

Kulick, D. and J. Rydström (2015), Loneliness and its Opposite: Sex, Disability, and the Ethics of Engagement (Durham: Duke University Press).

Landzelius, K. (2006), Going Native on the Net: Indigenous Cyberactivism and Virtual Diasporas over the World Wide Web (London: Routledge).

Lepp, M., and Dellenborg, L. (2013). Workshop med forumspel - framväxten av etnografiskt drama. [Workshop with Forum-Play - the Development of Ethnographic Drama], in C. Skott, L. Dellenborg, M. Lepp and K. Nässén (eds.), Människan i vården: Etno- grafi, vård och drama [The Person in Healthcare: Ethnography, Care and Drama] (Stockholm: Carlssons).

Lewin, K. (1946), 'Action Research and Minority Problems', Journal of Social Issues 2, no. 4: 34-46.

Long, D., C. L. Hunter and S. van der Geest (2008), 'When the Field Is a Ward or a Clinic: Hospital Ethnography', Anthropology \& Medicine 15, no. 2: 71-78.

Lundén, M., I. Lundgren, M. Morrison-Helme and M. Lepp (2017), 'Professional Development for Radiographers and Postgraduate Nurses in Radiological Interventions: Building Teamwork and Collaboration through Drama', Radiography: International Journal of Diagnostic Imaging and Radiation Therapy 23, no. 4: 330-336.

McCalman, J. and D. Potter (2015), Leading Cultural Change: The Theory and Practice of Successful Organizational Transformation (London: Kogan Page Limited).

Messerschmidt, D. A. (ed.) (1981), Anthropologists at Home in North America: Methods and Issues in the Study of One's Own Society (Cambridge: Cambridge University Press).

Mienczakowski, J. (2001), 'Ethnodrama: Performed Research - Limitations and Potential', in P. Atkinson (ed.), Handbook of Ethnography (London: SAGE).

Morrison, M., E. Nilsson and M. Lepp (2013), 'Bringing the Personal to the Professional: Pre-Service Teaching Students Explore Conflict through an Applied Drama Approach', Applied Theatre Research 1, no. 1: 63-76.

Nässén, K. (2013), ‘Deltagande observation' [Participant Observation], in C. Skott, L. Dellenborg, M. Lepp and K. Nässén (eds.), Människan i vården: Etnografi, vård och drama [The Person in Healthcare: Ethnography, Care and Drama] (Stockholm: Carlssons).

Rapport, N. (2009), Of Orderlies and Men: Hospital Porters Achieving Wellness at Work (Durham, NC: Carolina Academic Press).

Rice, T. (2003), 'Soundselves: An Acoustemology of Sound and Self in the Edinburgh Royal Infirmary', Anthropology Today 19, no. 4: 4-9.

Roper, J. M. and J. Shapira (2000), Ethnography in Nursing Research (Thousand Oaks, CA: SAGE).

Rosaldo, R. (2000). On Headhunters and Soldiers. Separating Cultural and Ethical Relativism. Issues in Ethics 11(1): 2-6.

Saldaña, J. (2008), 'Ethnodrama and Ethnotheatre', in J. G. Knowles and A. L. Cole (eds.), Handbook of the Arts in Qualitative Research: Perspectives, Methodologies, Examples, and Issues (Los Angeles: SAGE), 195-207.

Scott-Jones, J. and S. Watt (eds.) (2010), Ethnography in Social Science Practice (London: Routledge). 
Shestack, J. J. (2000), 'The Philosophical Foundations of Human Rights', in J. Symonides (ed.), Human Rights: Concepts and Standards (Aldershot, UK: UNESCO Publishing), 31-66.

Skott, C. (2013), ‘Beskriva, tolka och förstå - etnografins metodologi' [Description, Interpretation and Understanding - The Methodology of Ethnography], in C. Skott, L. Dellenborg, M. Lepp and K. Nässén (eds.), Människan i vården: Etnografi, vård och drama [The Person in Healthcare. Ethnography, Care and Drama] (Stockholm: Carlssons).

Skott, C., L. Dellenborg, M. Lepp and K. Nässén (2013), Människan i vården: Etnografi, vård och drama [The Person in Healthcare. Ethnography, Care and Drama] (Stockholm: Carlssons).

Snell, A. J., D. Briscoe and G. Dickson (2011), 'From the Inside Out: The Engagement of Physicians as Leaders in Health Care Settings', Qualitative Health Research 21, no. 7: 952-967.

Strathern, M. (1987), 'An Awkward Relationship: The Case of Feminism and Anthropology', Signs 12, no. 2: 276-292.
Street, A., and S. Coleman (2012), 'Introduction: Real and Imagined Spaces', Space and Culture 15, no. 1: 4-17.

Turner, V. (1982), From Ritual to Theatre: The Human Seriousness of Play (New York: PAJ Publications).

Turner, V. \& Turner, E. (1982). Performing ethnography. The Drama Review 26(2):33-50. Turner, V. (1986). The Anthropology of Performance. (New York: PAJ Publications).

Turner, V. and E. M. Bruner (eds.) (1986), The Anthropology of Experience (Urbana: University of Illinois Press).

van der Geest, S. and K. Finkler (2004), 'Hospital Ethnography: Introduction', Social Science and Medicine 59, no. 10: 1995-2001.

Wolf, A., I. Ekman and L. Dellenborg (2012), 'Everyday Practices at the Medical Ward: A 16-Month Ethnographic Field Study', BMC Health Services Research 12, no. 184: 1-12.

Zaman, S. (2008), 'Native among the Natives: Physician Anthropologist Doing Hospital Ethnography at Home', Journal of Contemporary Ethnography 37, no. 2: 135-154. 